\title{
Potential Plants for Treatment and Management of COVID-19 in Nigeria
}

Ikpa Chiyere B. C. (Corresponding Author)

Department of Chemistry, Imo State University, Owerri, Imo State, Nigeria

Email: cenyoh@gmail.com

\section{Maduka Tochukwu O. D.}

Department of Chemistry, Imo State University, Owerri, Imo State, Nigeria

Christian Ebere Enyoh

Department of Chemistry, Imo State University, Owerri, Imo State, Nigeria

\section{Ikezu Uju J. M.}

Department of Chemistry, Imo State University, Owerri, Imo State, Nigeria

\begin{tabular}{|l} 
Article History \\
Received: May 16, 2020 \\
Revised: June 19, 2020 \\
Accepted: June 22, 2020 \\
Published: June 25, 2020 \\
Copyright (C) 2020 ARPG \\
\& Author \\
This work is licensed \\
under the Creative \\
Commons Attribution \\
International \\
(4) (1) CC \\
BY: Creative Commons \\
Attribution License 4.0
\end{tabular}

Abstract

The recent outburst of novel Coronavirus disease (COVID-19), now a global pandemic highlights an urgent need for therapeutics targeting 'severe acute respiratory syndrome' (SARS-CoV-2). In Nigeria, infection cases are on daily rise with death rate of $\sim 3 \%$. Therefore, slowing the spread of the virus will significantly reduce the strain on the healthcare system and governments. Here, we presented local medicinal plants cultivated in Nigeria as possible therapeutic approaches, exclusively targeting SARS-CoV-2 and its pathways. The study focused on some plants containing bioactive compounds that showed promising results against previous coronaviruses. Potential plants identified include Zingiber officinale, Allium cepa, Allium sativum, echinacea, euphorbia hirta, Garcenea kola, Curcuma longa, Aleo vera and olea europaea. Although inhibition of viral replication is seen as the possible mechanism for antiviral activity of most of the natural compounds, recent research has shown that some natural compounds can interact with major viral proteins associated with virulence. Thereby, showing they could be a valuable tool for possible inhibition, management and treatment of SARS-CoV-2. However, further research is required to investigate and validate their potential use as antiSARS-CoV-2.

Keywords: Anti-SARS-CoV-2; CoVID-19; Medicinal plant; Nigeria; Pandemic; Treatment.

\section{Introduction}

Viral infections are known infectious diseases that will always trigger biological, clinical, and socio-economic problems worldwide. Recent global public health challenges have resulted from the emergence and reemergence of viral pathogens such as Middle East Respiratory Syndrome (MERS; in 2012, 2015, 2018) and Severe Acute Respiratory Syndrome (SARS; in 2002-2004) [1, 2]. Of utmost concern currently is the novel coronavirus which its susceptibility seems to be associated with age, biological sex, and other health conditions [3].

Novel coronavirus later named by World Health Organization [4] as COVID-19, was declared a public health emergency of international concern [1], due its high infection rate and global widespread [2]. As at April 28th 2020, the world had recorded 3.06 million infected persons, with 212 thousand deaths, and an estimated 907 thousand persons had recovered [5]. With the rate of spread and mortality of this disease, understanding the virulence mechanisms associated with these pathogens is a matter of urgency. The development effective remedies for early prevention as well as controlling future outbreaks depend on this knowledge.

Distributed broadly among birds, humans and other animals, coronaviruses has been reported to cause respiratory, gastroenteritis, hepatic, and neurologic diseases [6]. Prior to the 21th century, four human coronaviruses known (HCoV-NL63, HCoV-229E, HCoV-OC43 and HKU1) only caused mild common cold-type symptoms in immune-competent people [7, 8]. The first Human Coronaviruses of zoonotic origin were discovered in 2002 and 2012, they were linked to some fatal illnesses and have demonstrated the possibility of animal-to-human and humanto-human transmission. SARS-CoV was the causal agent of the severe acute respiratory syndrome outbreaks in 2002 which caused a SARS epidemic that resulted in $10 \%$ mortality. Similarly, the Middle East respiratory syndrome coronavirus (MERS-CoV) caused a devastating pandemic in 2012 with a $37 \%$ mortality rate [9].

When the genomics of the new virus was sequenced, it had a close $79.5 \%$ genetic sequence similarity with SARS-CoV [1] and it was named SARS-CoV-2 by the International Committee on Taxonomy of Viruses [9]. Given the spread of the new coronavirus and its impacts on human health, the research community has responded rapidly to the new virus and research is ongoing in all part of the world. As the infection spreads so fast, mortality piling by the hour, it seems unrealistic to synthesize, tests for safety and toxicity of a new drugs within such limited time. However, these constraints in time have led to repurposing of previous antiviral drugs to slow the rapid mortality effect of the virus. None has been very effective yet, and the search for vaccine and antiviral drugs is still ongoing. 
Some herbs have been reported to contain compounds possessing possible antiviral activity against SARS-CoV-2 $[10,11]$. The employment of these natural medicines can be a feasible and fast solution to this pandemic. Natural products and local medicine has been practiced in Nigeria for thousands of years and it is cheap and easily available. This review highlights the origin, structure, mechanism of spread and replication of SARS-COV-2, the symptoms, mode of transmission, mitigation and various treatment methods of the virus are described. Considering the low toxicity and availability of the plants, literature on local plants compounds as potential inhibitors of viral activities were also studied. This study was proposed with the aim of identifying herbal inhibitors of SARS-CoV-2, thereby locating a potential drug lead against the infections and also dietary supplements from those selected plants can be exploited by the locals to improve the immunity of the general population.

\section{Theory on the Origin of SARS-CoV-2}

In early 2020, controversies arose over the origin of SARS-CoV-2, while some researchers argued that the betacoronavirus was laboratory generated from a related SAR-CoV like coronavirus, other scientists' debated it was improbable to emerge through laboratory manipulations [12]. However, studies on the genetic data undeniably showed that SARS-CoV-2 is not genetic manipulated virus [12]. With this ideology, SARS-CoV-2 coronaviruses have been linked to animal origins, generally either in bats or rodents [13].

Previous outbreaks of Betacoronaviruses involved direct exposure of humans to animals; the viruses were transmitted directly to humans from civet cats (SARS-CoV) and dromedary (MERS-CoV) [14]. However, in this respect, researchers reported that COVID-19 may have been transmitted to humans via pangolin [15] or other wild animals [16] sold at the seafood market, where a number of animals and birds may be the reservoirs of this virus [17]. Following this trend, phylogenetic analysis showed that COVID-19 is similar to the CoVs circulating in Rhinolophus (horseshoe bats) as the Bat strain had the highest nucleotide resemblance Ji, et al. [18]. The exact origin of the virus continues to remain as a mystery to researchers worldwide. The propoposed pathway oof SARS-COV-2 is shown in Figure 1. The virus originating from the bat through an intermediary animal to the first humans where it gains momentum into human to human spread

Figure-1. Proposed pathway of the origin of SARS-CoV-2

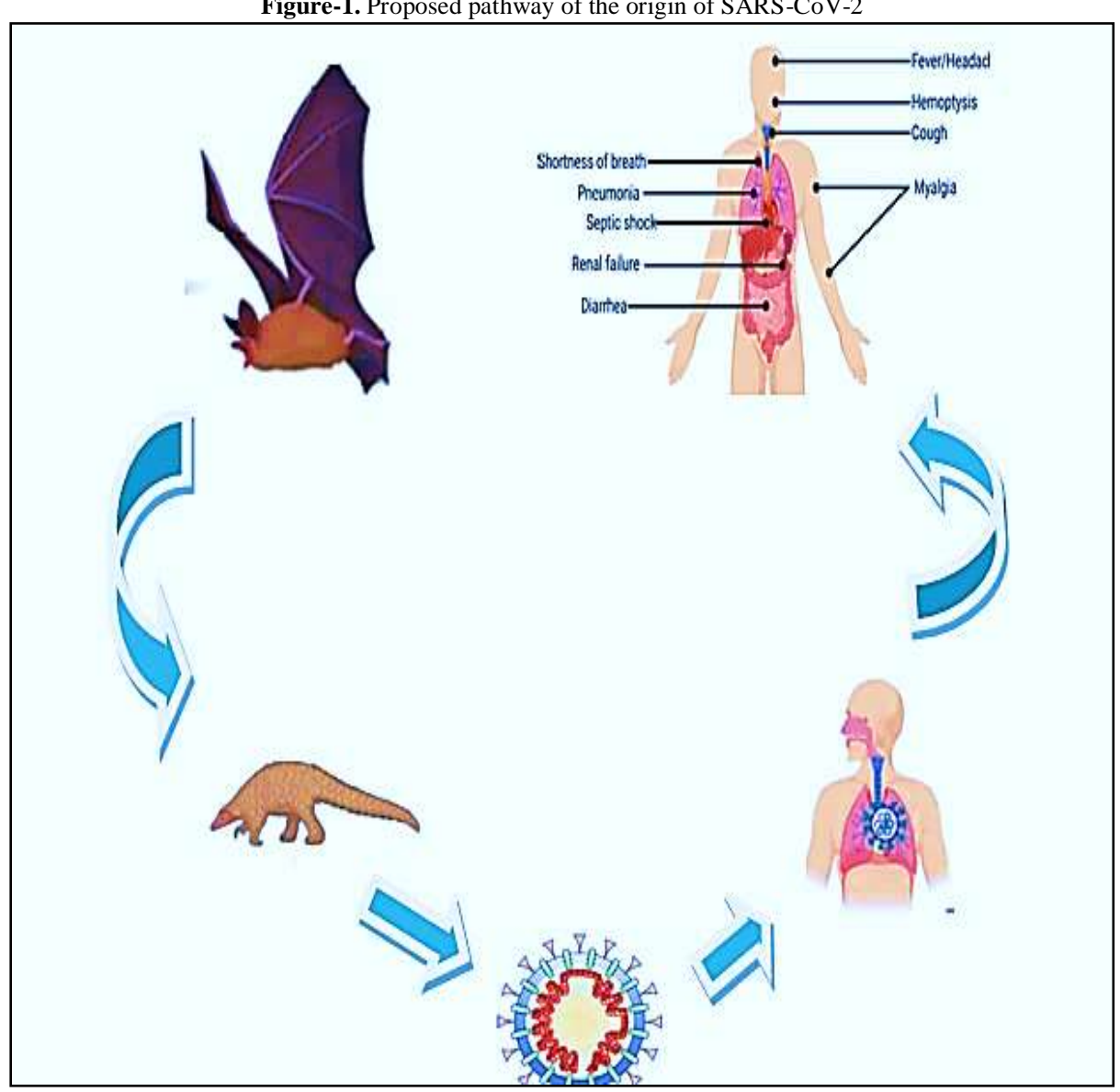

\section{Structure and Replication of Coronavirus}

Coronavirus name was derived from the Latin word corona which means crown. This name was coined from the virus structure whose surface projections on the viral envelope appear crown-like. The virus is a single-stranded positive-sense RNA virus with a genome of around 28-32 kb in length, making it the largest RNA viruses ever existed [19]. Observations made on the Coronaviruses show that they share a similar structure composed of four important structural proteins: spike $(\mathrm{S})$, membrane $(\mathrm{M})$, envelope $(\mathrm{E})$, and nucleocapsid $(\mathrm{N})$ proteins presented in Figure 2 Susan and Sonia [20]. The viral particles consist of an internal helical RNA-protein nucleocapsid phosphoprotein surrounded by an envelope containing viral glycoproteins. Spike glycoprotein (S) forms the large 
glycosylated peplomers that are characteristic of coronaviruses. $M$, the transmembrane protein, is highly hydrophobic and spans the membrane three times. E, a membrane-spanning protein, is a minor component of the membrane. It is recognized that these structural proteins aid the viral infection of host cells and subsequent replication $[19,21]$. The Spike protein is responsible for attachment to host receptors, membrane protein helps shape the virion particles and binding to nucleocapsid, Envelope protein plays a role in the assembly and release of particles while nucleocapsid protein aids with the binding of the genome to a replication-transcription complex which is required for the replication of genomic material [21].

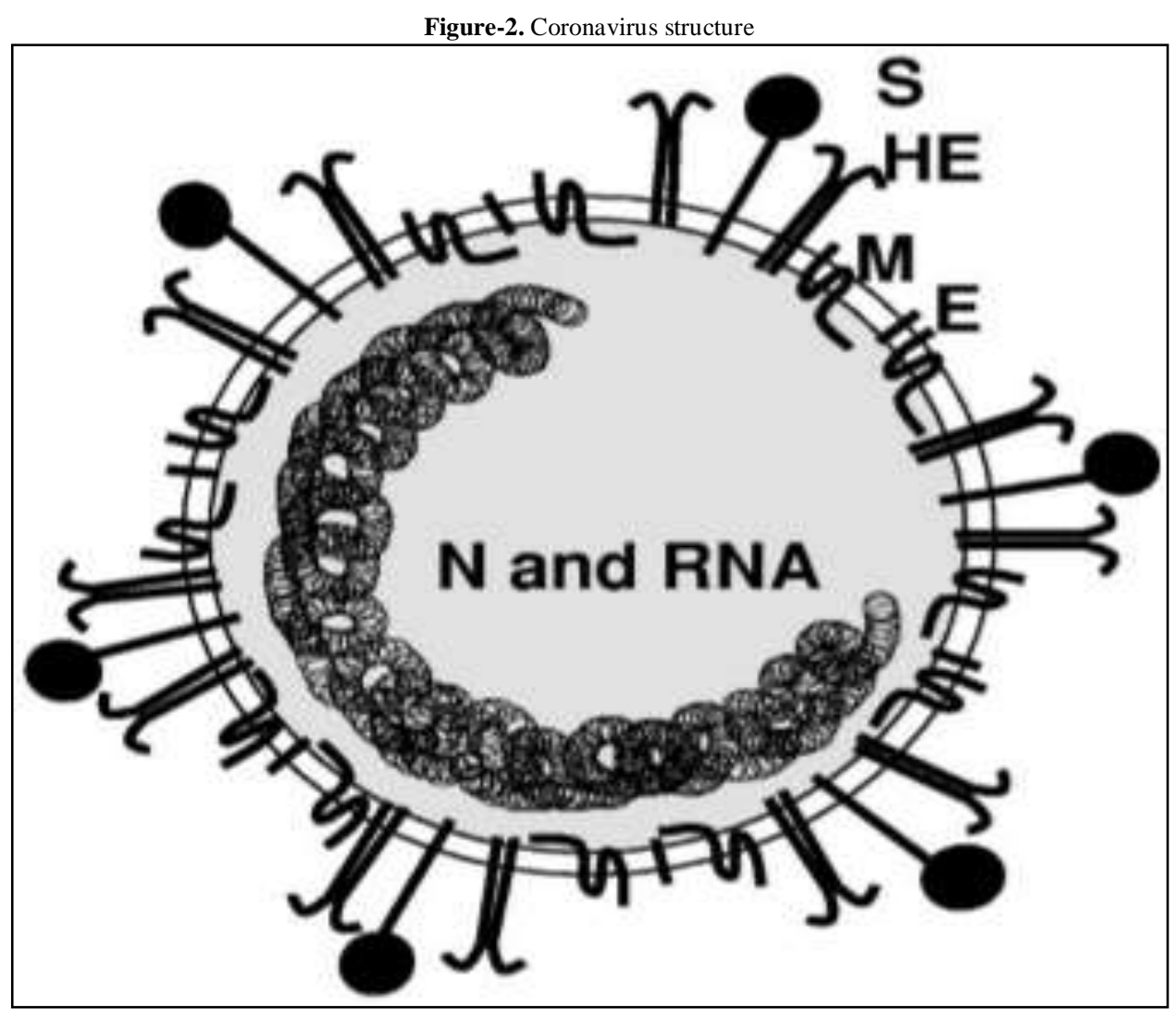

According to Zhang, et al. [22], SARS-CoV and SARS-CoV-2 have similar receptors, exclusively expressed at the receptor binding domain (RBD) and the receptor binding motif (RBM) in the viral genome. At the beginning of the viral infections, the RBM of the S protein attaches directly to the Angiotension-Converting Enzyme 2 (ACE2) of the host cells $[23,24]$. The expression of the ACE2 protein can be found in various organs of the human body mainly in the lungs, kidney and intestine, these organs pose as prime targets for the coronavirus. After the SARSCoV-2 virus has entered the human cells its next target is replication of its RNA. SARS-CoV-2 and SARS-CoV has similar virus replication mechanism which is complicated and needs more understanding [22, 23]. During the replication stage, the replicate gene encoded enzymes uses the negative RNA genome as a model to assemble a few sets of small, overlapping messenger RNA (mRNA) molecules that are further translated into the structural proteins, while the positive stranded RNA genome is used as a template to produce the negative strand. Replication process in the human host involves the $\mathrm{N}$ protein binding to the genome while the $\mathrm{M}$ protein couples with the membranes of the endoplasmic reticulum (ER). Furthermore, the RNA gets assembled into a helical twisted structure and buds into the ER lumen with the help of nuclear shuttle proteins (Nsp). Lastly, the Golgi bodies transfers the viral progenies to the cell membranes and they are exocytosed into the extracellular space of the human host cell environment [21, 25].

\section{Symptoms, Mode of Transmission, Mitigation and Treatment Methods}

SARS-CoV-2 infects people in different ways, which may be direct (human to human contact) or indirect (contact with contaminated inanimate surfaces) [2, 26]. Most infected persons develop mild to moderate symptoms requiring no special treatment till recovery. People with underlying medical conditions such as people with chronic lung disease or moderate to severe asthma, serious heart conditions, immune-compromised persons, severe obesity (with body mass index $[\mathrm{BMI}] \geq 40$ ), people with diabetes, chronic kidney disease undergoing dialysis, liver disease and older folks are at a higher risk of developing severe disease and death [27].

The COVID-19 is known to show symptoms slowly over an incubation period of around 2 weeks. During this time the virus replicates in the upper and lower respiratory tract, forming lesions [28]. The common symptoms exhibited by infected individuals include tiredness, fever, cough, dyspnea, sore throat/lesion in the lungs, aches and pains and very few people will report diarrhoea, nausea or a runny nose [29] with highest occurrence of fever (87.9 $\%)$ and the least is conjunctival congestion $(0.8 \%)$. The overall occurrence distribution of signs and symptoms is presented in Figure 3. In the advanced stage, pneumonia is markedly observed in patients which progresses to severe pneumonia and acute respiratory distress syndrome (ARDS) resulting to need for life -support [30]. 
Figure 3. Occurrence of signs and symptoms of COVID-19 (reproduced from WHO [31]

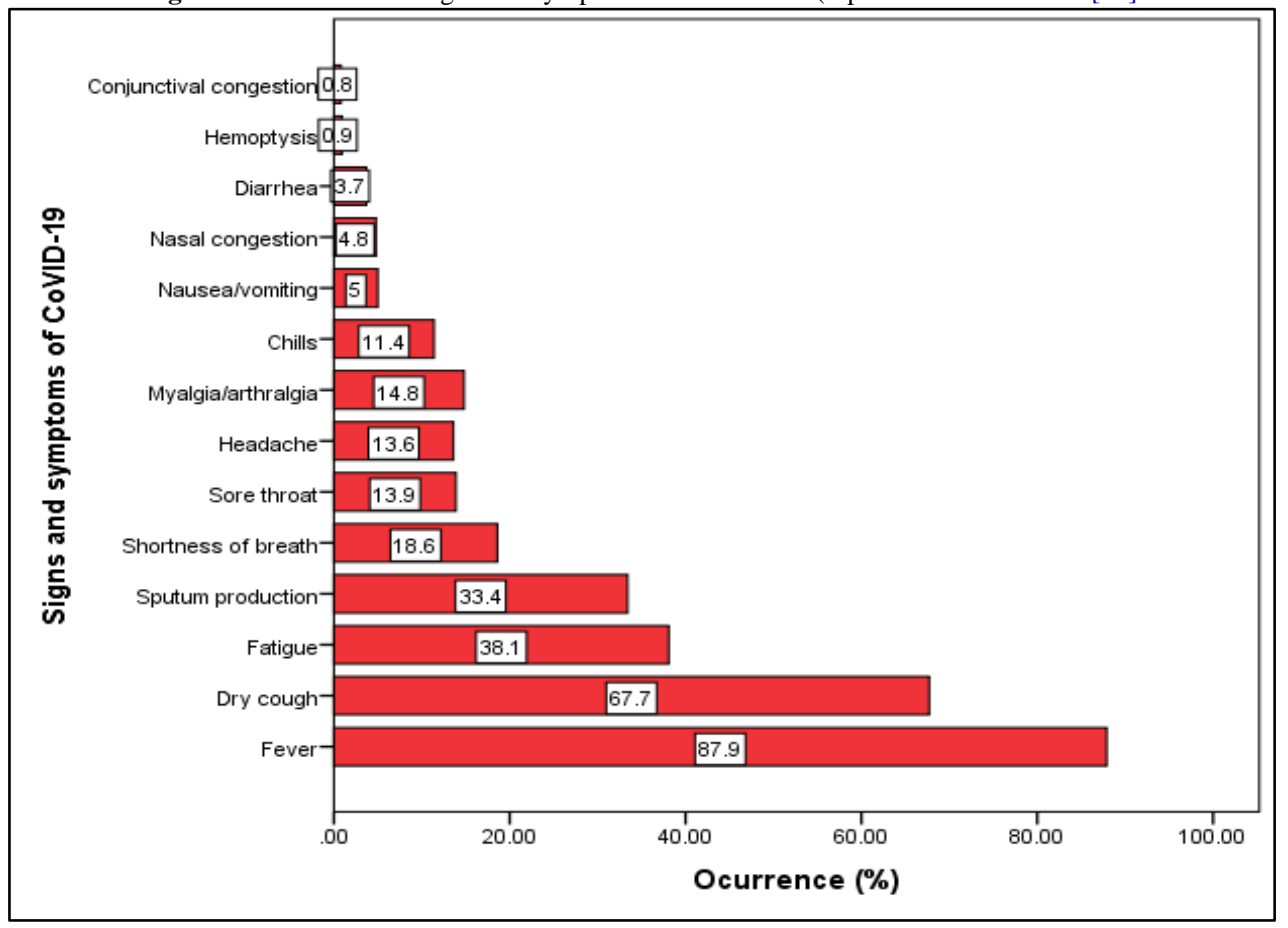

The virus is transmitted mainly by symptomatic people although there are suggestions that individuals who remain asymptomatic could transmit the virus [26]. The possibility of transmission before symptoms develop seems to be infrequent, although it cannot be excluded thereby suggesting that the use of isolation is the best preventive measure for containing this epidemic. According to current information, the mode of human-human transmission of SARS-CoV-2 is primarily through respiratory droplets and contact media. Droplet transmission occurs when a person is within $1 \mathrm{~m}$ radius of an infected person, therefore is at risk of having his/her mucosae (mouth and nose) or conjunctiva (eyes) exposed to infective respiratory droplets [4]. However, recent studies have suggested that the virus may be transmitted beyond $3 \mathrm{~m}$ and therefore exposing the possibility of long distance transport of droplet [26]. Furthermore, transmission of SARS-CoV-2 can occur by either having direct contact with infected people and indirectly by coming in contact with surfaces in the immediate environment or with objects used by or on the infected person. Airborne transmission has also been discussed but this mode of transmission of the virus may be possible in specific circumstances in which high level of aerosols is generated and recently through fart although this mechanism is not properly defined $[2,26]$. Overview of transmission pathway of SARS-CoV-2 based on current information is presented in Figure 4.

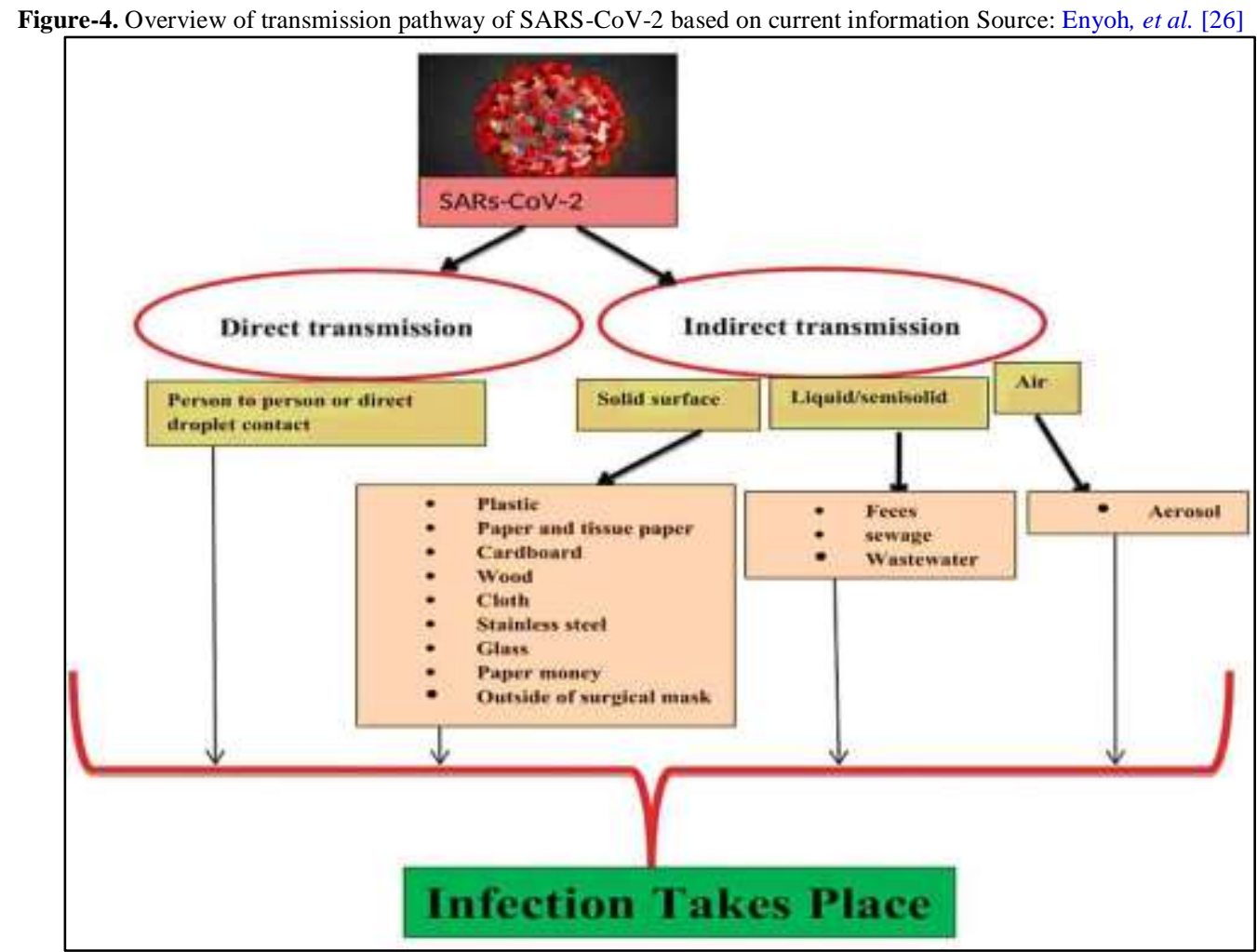


Currently, there are no approved or universally recommended therapies or vaccines for SARSCoV-2. Plasma and antibodies obtained from the convalescent patients have been proposed for use in treatment. In addition, various vaccine strategies, such as using inactivated viruses, live-attenuated viruses, viral vector-based vaccines, subunit vaccines, recombinant proteins, and DNA vaccines, have been developed but have only been evaluated in animals so far. Since no effective therapy or vaccine in existence right now, current possible measures are to control the source of infection, by early diagnosis, reporting, isolation, supportive treatments for infected persons, good personal hygiene, wearing fitted mask, ventilation, and avoiding crowded places. The major steps taken by China, which can be adopted globally in controlling the pandemic is presented in Figure 5.

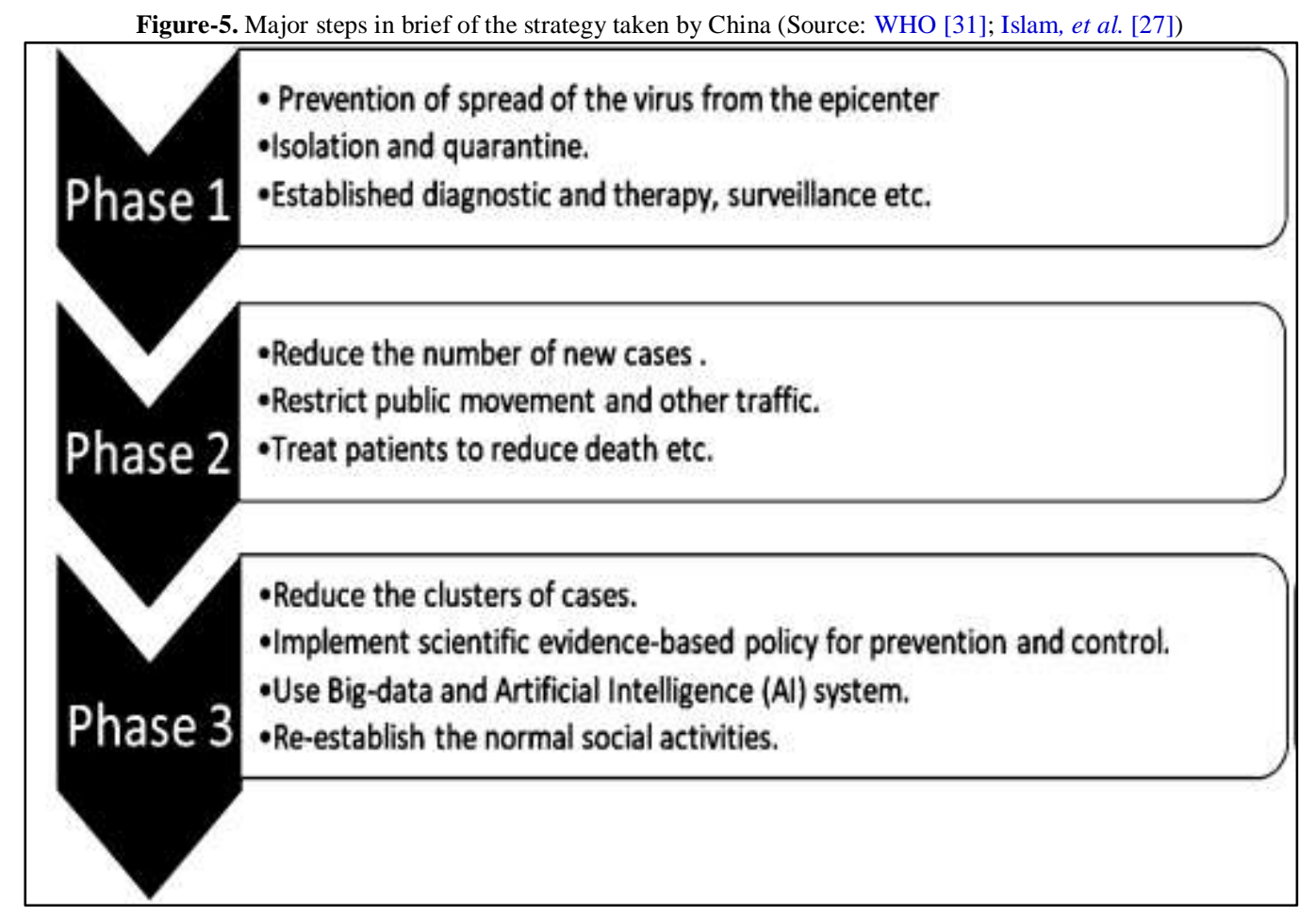

\section{Novel Coronavirus in Nigeria}

The first case of SARS-CoV-2 in Nigeria was confirmed in an Italian citizen in Lagos in February 27, 2020. The second case was recorded in Ogun State on 9 March 2020, in a Nigerian citizen who had contact with the first case [32]. Ever since, the number of cases in on continual increase reaching a total of 1532 cases with 255 recovery cases and 44 deaths as of $29^{\text {th }}$ April, 2020 (Figure 6). The age-sex distribution of confirmed cases presented in Figure 7 showed that male had the higher cases in the age group of 31-40. With the increasing widespread of the virus and death in Nigeria coupled with poor health care system, there are needs to look within our ecosystem and search for remedies for the virus.

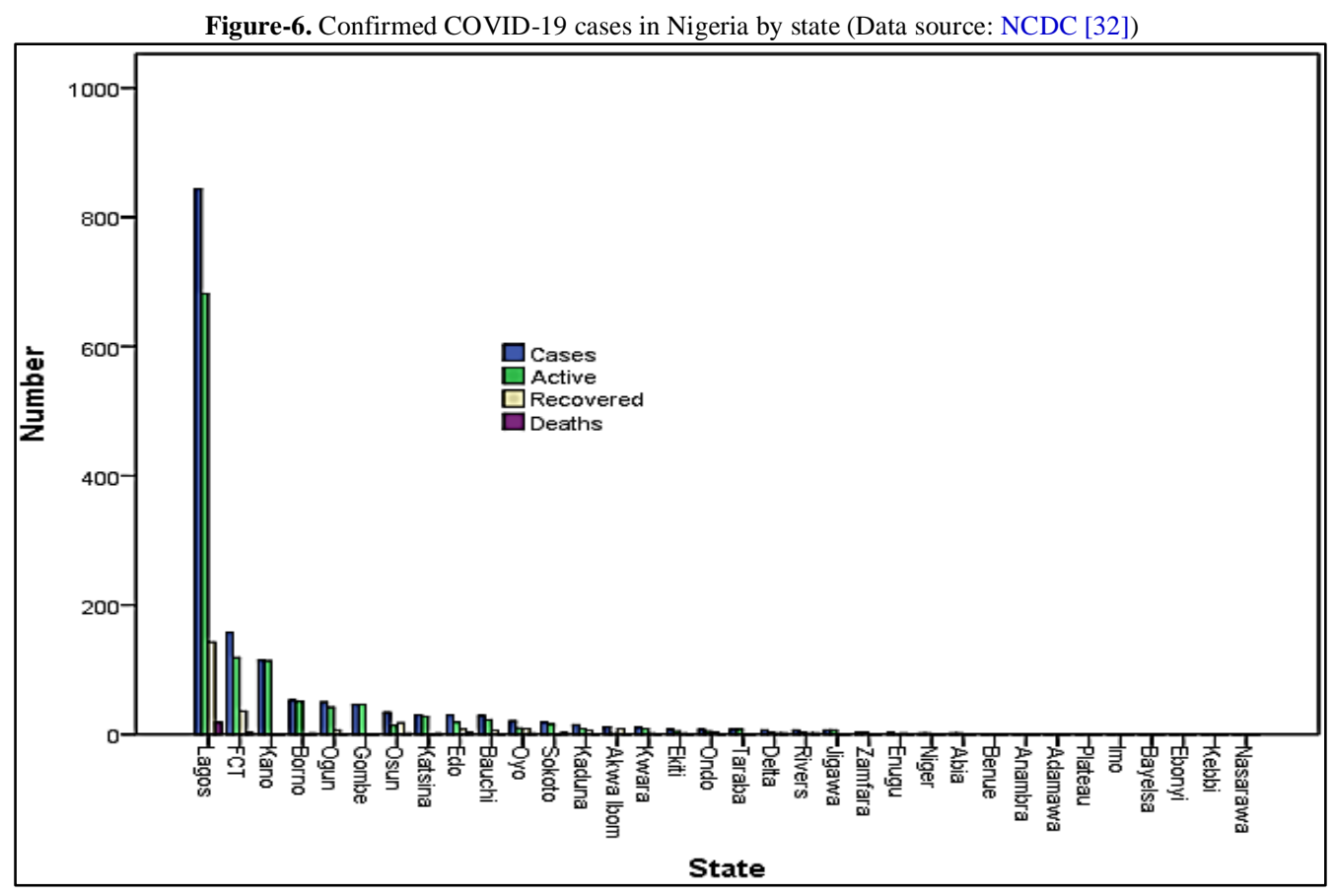




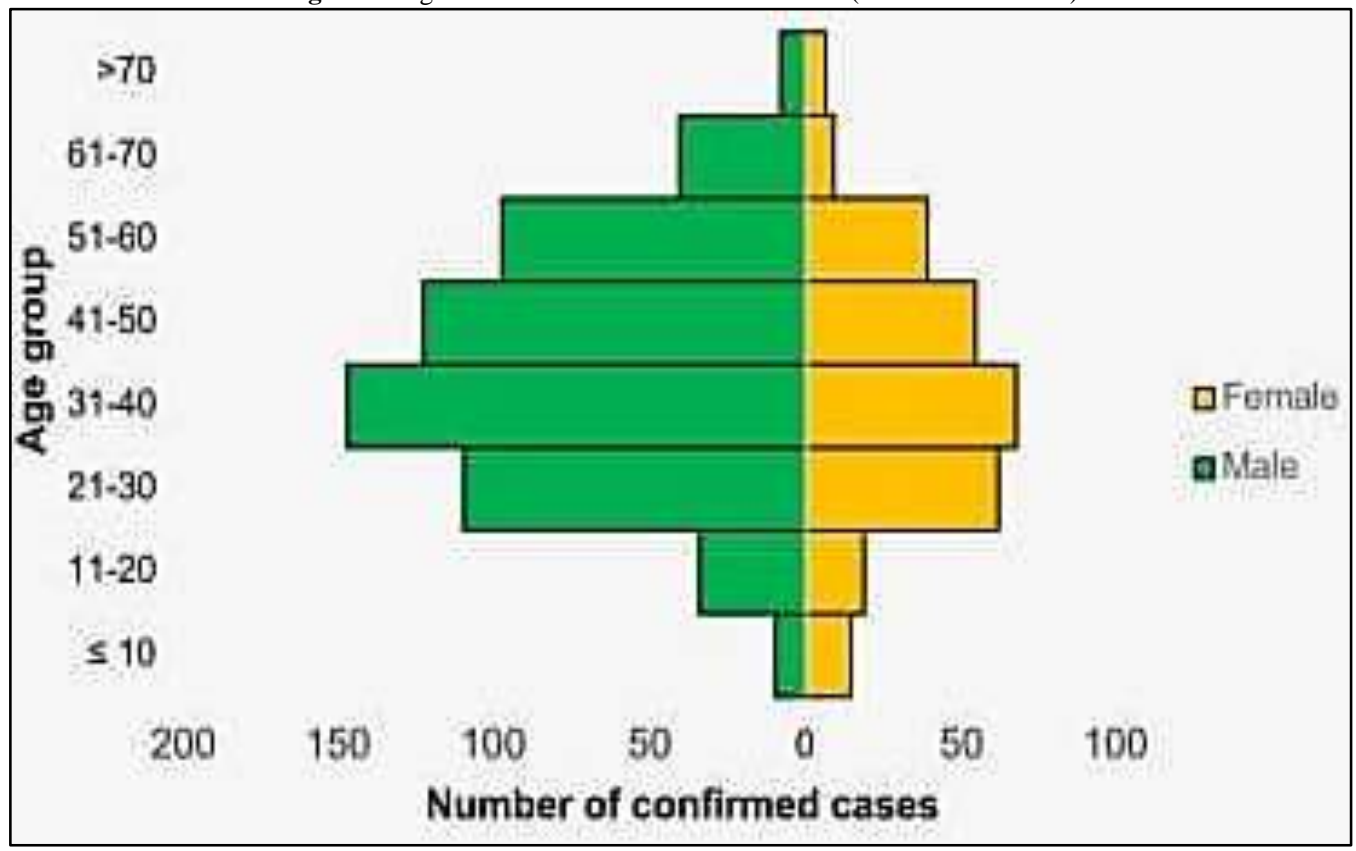

\section{Potential Herbal Remedies to Combat Coronavirus}

The simplest route to combating SARS-CoV-2 would be to deactivate the virus route to entering cells as this has been utilized in previous viruses of its kind [33]. Reports made by several groups have suggested the use of some natural compounds have potency to inhibit SARS-CoV activity. Traditional medicine has been suggested in China, India and other regions of the world for the treatment of COVID-19. There is significant evidence showing the effectiveness of the herbal medicine [34-37], for example data reported by the National Health Commission of the People's Republic of China showed that at the national level 74,187 infected patients used traditional Chinese medicine and in Hubei Province 61,449 infected patients. From the clinical observation, the efficacy of treatment rate was above 90\% [38]. Reports for traditional herbal medications against COVID-19 have been documented in Thailand [39], India [40], Bolivia [41] and Tunisia [42]. In Madagascar, the use of herbal medicines as antivirus has been legalized and produced in large quantities.

Although, the mechanisms of this treatment have not been clearly understood, identification of the antiviral mechanisms from these natural agents will shed light on where they interact with the viral life cycle, such as viral entry, replication, assembly, and release, as well as on the targeting of virus-host-specific interactions. Our proposed mechanism is the use of the herbs for interactions such as inhibiting the viral 3CL protease and blocking the viral RNA-dependent RNA polymerase activity. Nine carefully selected herbs cultivated in Nigeria which include Ginger (Zingiber officinale), onions (Allium cepa), Garlic (Allium sativum), Echinacea, Euphorbia hirta, Garcenea kola, Turmeric (Curcuma longa), Aleo vera and Olive (olea europaea), have been reported to contain compounds capable of inhibiting a variety of viruses. These plants have been selected in the review and their bioactive compounds and their antiviral compounds highlighted (Table 1).

Table-1. Potential plants, compound of interest and some therapeutic history

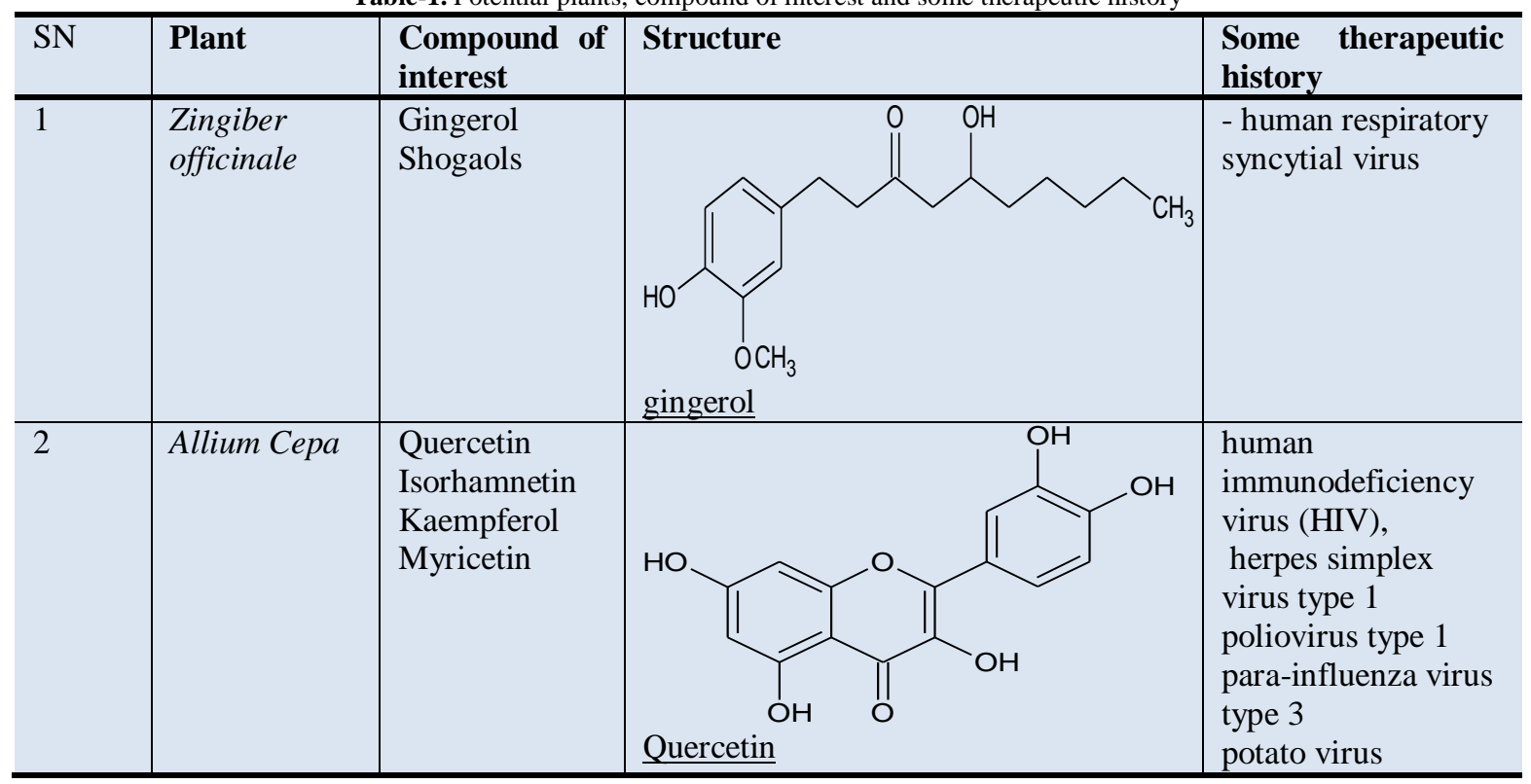




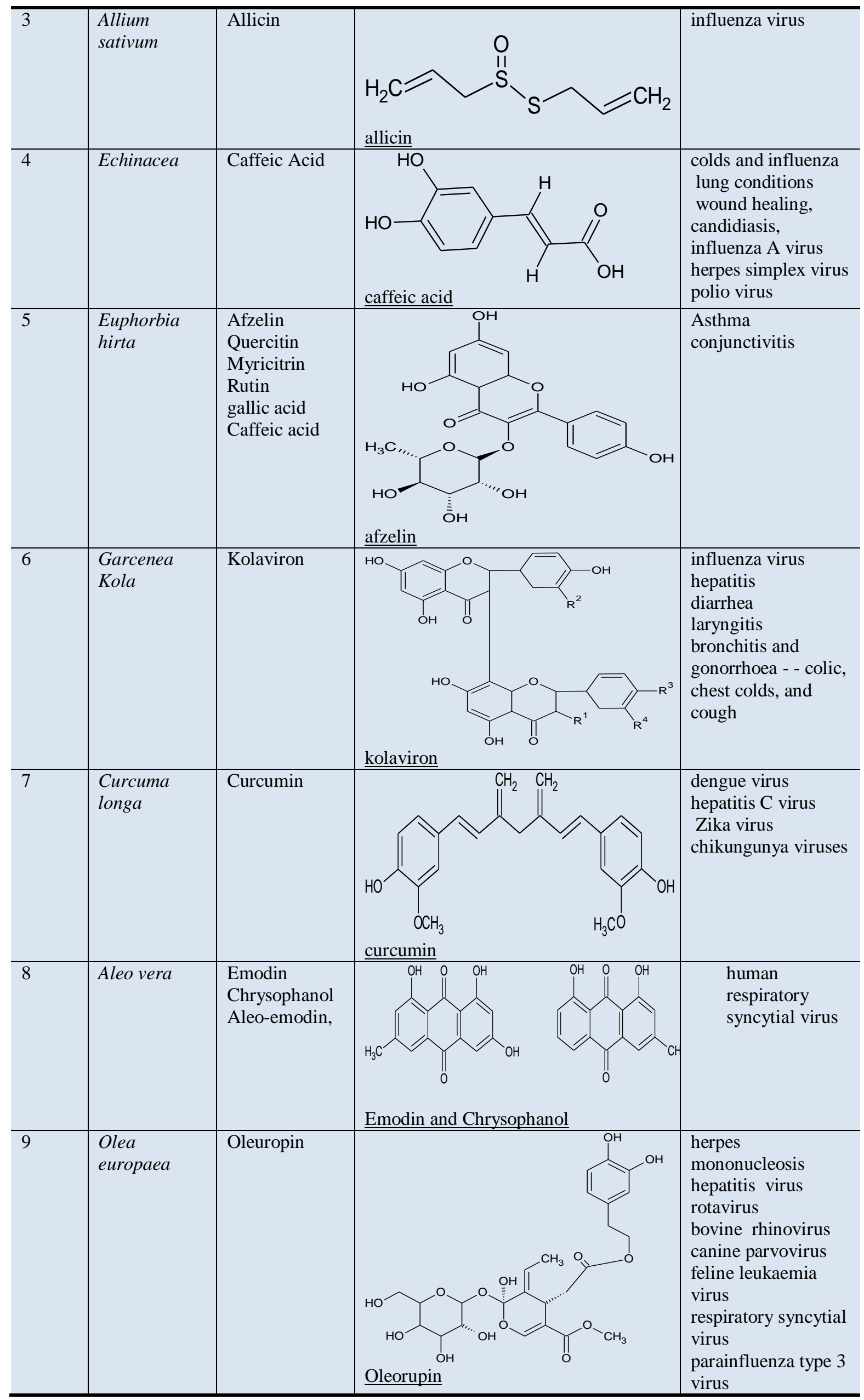




\subsection{Zingiber Officinale Roscoe}

Ginger (Zingiber officinale) is a common and widely used spice. It is rich in various chemical constituents, including phenolic compounds, terpenes, polysaccharides, lipids, organic acids, and raw fibers. The health benefits of ginger are mainly attributed to its phenolic compounds, such as gingerols and shogaols [43]. Researchers have confirmed that ginger possesses multiple biological activities, including antioxidant, anti-inflammatory, antimicrobial, anticancer, neuroprotective, cardiovascular protective, respiratory protective, antiobesity, antidiabetic, antinausea, antiviral and antiemetic activities. Fresh ginger possesses anti-viral activity against human respiratory syncytial virus due to the presence of bioactive phenolic phytocompounds [44]. These have been found to inhibit viral replication and prevent viruses from entering host cells. Report of Virtual screening of gingerol performed against some replication protease of SARS-COV-2 showed the potential ability of ginger to serve as putative remedy to the COVID-19 [45].

\subsection{Allium Cepa}

Allium cepa (onion) belongs to the Liliaceae family and is known to contain many phytochemicals such as carotenoids, copaenes, flavonoids, minerals, phenolics, phytoestrogens, terpenoids, vitamins, anthocyanins, and amino acids [46]. The plant have been reported to possess several therapeutic properties such as antimicrobial activity, antiparasitic, antiviral, antifungal, antioxidant and anti-inflammatory effects [47]. There is data on the inhibitory effects of A. cepa against human immunodeficiency virus (HIV), herpes simplex virus type 1, poliovirus type 1, para-influenza virus type 3, and potato virus [48, 49]. Organosulfur compounds like Isorhamnetin, Kaempferol, Quercetin, Myricetin found in the plant are associated with inhibition of viral infection [50]. These chemicals can hinder virus attachment to host cell, alter transcription and translation of viral genome in host cell and also affect viral assembly. Quercetin can affect entry and attachment of Enterovirus and Influenza virus on host cell [47]. These compounds have also been tipped as a potential inhibitor and antiviral herb against the SARS-COV-2 [10].

\subsection{Allium Sativum}

Allium sativum (garlic) may be one of the most famous herbal remedies to be used by humans in history dating back to ancient cultures. Garlic has been an interesting plant for centuries as a medicinal panacea. Broad range of pathogenic organisms, including bacteria, fungi, protozoa and viruses has been shown to be sensitive to fresh crushed garlic [51]. The main active component of Fresh garlic extracts "allicin". This active compound has been shown to possess antiviral activity in vitro and in vivo studies. Its beneficial effects may be due in part to sulfurcontaining compounds such as allicine, diallyl disulfide, diallyltrisulfide that react with thiol groups of various enzymes which are critical for microorganism surveillance. A report by Mehrbod, et al. [51] showed the antiviral activity of A. sativum against influenza virus in cell culture. Molecular docking of the main component against Main protease of SARS-COV-2 shows that it is a potential inhibitor for replication of the Virus [10].

\subsection{Echinacea}

Modern medicinal uses of Echinea are supported in literature as they have been used for treatment of colds and influenza, lung conditions, wound healing and candidiasis, and various other topical and systemic conditions [52]. Further, it has been tipped as a remedy for treatment of respiratory infections [53]. In view of the current popularity of Echinacea preparations in the prevention and treatment of upper respiratory symptoms, it is tempting to speculate that antiviral activities are present, and indeed there have been a few reports of anti-HSV activity and anti-influenza A virus activity of the plant [54]. Based on this, the plant may be used in treating COVID-19 as the disease share similar signs and symptoms. The presence of caffeic acid in the plant has been seen as the bioactive compound responsible for pharmacological property. Caffeic acid has been shown to inhibit the multiplication of influenza A virus in vitro, Caffeic acid has also been shown to have antiviral activity against herpes simplex virus (DNA virus) and polio virus (RNA virus).

\subsection{Euphorbia Hirta}

Euphorbia hirta also called the asthma herb is a medicinal weed located in many parts of Africa, Asia, and Australia. It has been used locally in the treatment of gastrointestinal disorders, bronchial and respiratory diseases [55]. Other properties have also been recorded for E. hirta, e.g. hypotensive, tonic, antipyretic, anti-inflammatory and sedative effects [56]. The latex of the plant is used in the treatment of conjunctivitis, fresh wounds and burns. Previous phytochemical studies on this plant have revealed the presence of diterpenoids, triterpenoids and flavonoids [57] while hydrolysable dimericellagitannins (euphorbin A,B, C and E) have been isolated from the leaves of the plant [56]. Other researcher has detected quercitin, myricitrin, rutin, gallic acid, caffeic acid, afzelin and more medicinal compounds in the plant [58-60]. The plant parts have been assayed by various researchers for antiviral activity, and the striking presence of these phytochemicals has been reported to be responsible for its antiviral activity [61]. Some compounds present in the plant like Quecertin, Caffeic acid and afzelin have been tipped to be inhibitors of SAR-COV-2 [10].

\subsection{Garcinia Kola}

Garcinia kola belongs to the family Guittiferae, the English name is bitter kola and it is commonly cultivated in all parts of Nigeria. The plant has been referred to as a "wonder plant" because every part of it has been found to be 
of medicinal importance [62]. G. kola is used in folklore remedies for the treatment of ailments such as liver disorders, hepatitis, diarrhea, laryngitis, bronchitis and gonorrhoea [63, 64]. The seed is masticatory and also used to prevent and relieve colic, chest colds, and cough and can as well be used to treat headache [65]. The medicinal properties of the plant are due to the presence of the biflavonoid Kolaviron. Kolaviron the antiviral compound in Garcinia kola has been reported to suppress mortality mice infected with influenza virus [66]. Locally, it has been tipped by herbalists as a putative anti-SAR-COV-2.

\subsection{Curcuma Longa}

Turmeric (Curcuma longa) is an ancient coloring spice of Asia, currently found in northern Nigeria as the main source of curcumin. It is traditionally used for many remedies to various conditions. Curcumin, due to a variety of specific characterizations is in interest of scientists in recent years. It has been used as a food additive and herbal supplement due to its potential medicinal properties. It has been found to exhibited antiviral properties against several viruses, including dengue virus and hepatitis $\mathrm{C}$ virus, Zika and chikungunya viruses [67]. Recent molecular docking studies result showed that Curcumin is a potential inhibitor of the SARS-CoV-2 [10].

\subsection{Aloe Vera}

Aloe vera has been used for medicinal purposes in several cultures for millennia: Greece, Egypt, India, Mexico, Japan and China [68]. This plant is recently cultivated in all parts of as an ornamental plant as well as for medicinal use. Aloe vera leaves has been reported to have antiviral, anti-inflammatory, antibacterial properties. It contains anthraquinone derivatives like aleo-emodin, emodin and chrysophanol reportedly exhibiting antiviral activity [69]. The potential inhibition activity of aleo vera against SARS-COV-2 has been reported by Ambrish, et al. [70].

\subsection{Olea Europaea}

Olive (Olea europaea) is native to the Mediterranean region and is main component of the Mediterranean diet. The oil has been used for both diet and spiritual purposes, the leaves have been widely used as a folk remedy in traditional medicine [71].The plant has been reported to possess several pharmacological properties including antioxidant, anti-inflammatory, anti-atherogenic, anti-cancer, antimicrobial and antiviral [72]. The main active constituents of olive plant include oleic acid, phenolic constituents, and squalene [73]. Oleuropein is generally the most prominent phenolic compound in olive cultivars [73]. Olive leaf extract has been claimed in a U.S. patent to have potent antiviral activities against herpes mononucleosis, hepatitis virus, rotavirus, bovine rhinovirus, canine parvovirus, and feline leukaemia virus [72]. In addition, the leaf extracts has exhibited a significant antiviral activity against respiratory syncytial virus and parainfluenza type 3 virus [73]. The molecular docking of Oleuropin against SARS-COV-2 main protease has shown the potential use of oleuropin as an inhibitor of SARS-COV-2 as reported by Siti, et al. [10].

\section{Conclusion}

As the days roll by, SARS-COV-2 harvest the weaker immune members of the populace increasing death toll, economic breakdown in states and countries are besieged by poverty. All round the clock effort of researchers and medical practitioners yields little effort as there is no positive sign of a synthetic antivirus or vaccines to end the pandemic situation. Drug repurposing has been done and various drugs have been used to treat the symptoms exhibited by persons infected with SARS-CoV-2. Some researches remind us of our earliest source of side effect free drugs. Local medicines have been utilized for treating the symptoms of COVID-19 in many parts of the world and it has been effective. Our review suggests the importance of a few medicinal plants in Nigeria that have been used for decades in treating various respiratory ailments. It highlights the pathways that the plant-based medicines may target SARS-COV-2 to reduce the burden of COVID-19 in the absence of vaccines and synthetic drugs. Thus, proactive investments in researches in natural product as a means to derive vaccines or drugs to treat COVID-19 can bring resounding hope to overcome this fatal infection.

\section{References}

[1] Zhu, N., Zhang, D., Wang, W., Li, X., Yang, B., Song, J., Zhao, X., Huang, B., Shi, W., et al., 2020. "A novel coronavirus from patients with pneumonia in China, 2019." N. Engl. J. Med., vol. 382, pp. 727-733.

[2] Enyoh, C. E., Verla, A. W., and Verla, E. N., 2020. "Novel coronavirus (SARS-CoV-2) and airborne microplastics." Zenodo, Available: http://doi.org/10.5281/zenodo. 3738452

[3] WMHC, 2020. "Wuhan municipal health and health commission's briefing on the current pneumonia epidemic situation in our city." Available: http://wjw.wuhan.gov.cn/front/web/showDetail/2019123108989

[4] World Health Organization, 2020. "Novel Coronavirus (2019-nCoV) situation report." Available: https://www.who.int/emergencies/diseases/novel-coronavirus2019/situation-reports

[5] Wordometer, 2020. Available: https://www.worldometers.info/coronavirus/\#countries

[6] Na, Z., Dingyu, Z., Wenling, W., Xingwang, L., Bo, Y., Jingdong, S., Xiang, Z., Baoying, H., Weifeng, S., et al., 2020. "A novel coronavirus from patients with pneumonia in China, 2019." N. Engl. J. Med., vol. 382, pp. 727-733.

[7] Masters, P. S. and Perlman, S., 2013. Coronaviridae. In: Knipe dm, howley pm, eds. Fields virology. 6th ed. Lippincott Williams and Wilkins, pp. 825-58.

[8] Weiss, S. R. and Leibowitz, J. L., 2011. "Coronavirus pathogenesis." Adv. Virus. Res., vol. 81, p. 85164. 
[9] Firas, A. R., Mazhar, S. A. Z., Ghena, A. K., Dunia, M. S., and Amjad, D. A.-N., 2020. "SARS-CoV-2 and coronavirus disease what we know so far." Pathogens, vol. 9, p. 231.

[10] Siti, K., Hendra, K., Rizki, A., Suhartati, S., and Soetjipto, S., 2020. "Potential Inhibitor of COVID-19 Main Protease (Mpro) from Several Medicinal Plant Compounds by Molecular Docking Study." Available: http://doi:10.20944/preprints202003.0226.v1

[11] Li, S. Y., Chen, C., and Zhang, H. Q., 2005. "Identification of natural compounds with antiviral activities against SARS-associated coronavirus." Antivir Res., vol. 67, pp. 18-23.

[12] Pei, H., Wu, Z., Shiyang, S., Shiyong, F., and Xuan, L., 2020. "Is SARSCoV-2 originated from laboratory?. A rebuttal to the claim of formation via laboratory recombination." Emerging Microbes and Infections, vol. 9, pp. 545-547.

[13] Chan, J. F. W., Kok, K. H., Zhu, Z., Chu, H., To, K. K. W., Yuan, S., and Yuen, K. Y., 2020. "Genomic characterization of the 2019 novel human-pathogenic coronavirus isolated from a patient with atypical pneumonia after visiting Wuhan." Emerg. Microbes Infect., vol. 9, pp. 221-236.

[14] Nassar, M. S., BaKhreBah, M., MeoSa, a., and ZaherWa, M. S., 2018. "Middle East Respiratory Syndrome Coronavirus (MERS-CoV) infection: epidemiology, pathogenesis and clinical characteristics." Eur. Rev. Med. Pharmacol. Sci., vol. 22, pp. 4956-4961.

[15] Lam, T. T., Shum, M. H., and Zhu, H. C., 2020. "Identification of 2019-nCoV related coronaviruses in Malayan pangolins in southern China." Available: https://doi.org/10.1101/2020.02.13.945485

[16] Lu, R., Zhao, X., Li, J., Niu, P., Yang, B., Wu, H., Wang, W., Song, H., Huang, B., et al., 2020. "Genomic characterization and epidemiology of 2019 novel coronavirus: implications for virus origins and receptor binding." Lancet, Available: https://doi.org/10.1016/S0140-6736(20)30251-8

[17] Mingxuan, X. and Qiong, C., 2020. "Insight into 2019 novel coronavirus — an updated intrim review and lessons from SARS-CoV and MERS-CoV." Available: https://doi.org/10.1016/j.ijid.2020.03.071

[18] Ji, W., Wang, W., Zhao, X., Zai, J., and Li, X., 2020. "Cross-species transmission of the newly identified coronavirus 2019-nCoV." J. Med. Virol., vol. 92, pp. 433-440. Available: https://doi.org/10.1002/jmv.25682

[19] Schoeman, D. and Fielding, B. C., 2019. "Coronavirus envelope protein: Current knowledge." Virology. J., vol. 16, p. 69. Available: https://doi.org/10.1186/s12985-019-1182-0

[20] Susan, R. W. and Sonia, N.-M., 2005. "Coronavirus pathogenesis and the emerging pathogen severe acute respiratory syndrome coronavirus." Microbiol. Mol. Bio.l Rev., vol. 69, pp. 635-664.

[21] Vellingiri, B., Jayaramayya, K., and Iyer, M., 2020. "COVID-19: A promising cure for the global panic." vol. 2, Available: https://doi.org/10.1016/j.scitotenv.2020.138277

[22] Zhang, L., Lin, D., Sun, X., Curth, U., Drosten, C., Sauerhering, L., Becker, S., Rox, K., and Hilgenfeld, R., 2020. "Crystal structure of SARS-CoV-2 main protease provides a basis for design of improved $\alpha$ ketoamide inhibitors. Science. eabb3405." Available: https://doi.org/10.1126/science.abb3405

[23] Ksiazek, T. G., Erdman, D., Goldsmith, C. S., Zaki, S. R., Peret, T., Emery, S., Tong, S., Urbani, C., Comer, J. A., et al., 2003. "A novel coronavirus associated with severe acute respiratory syndrome." $N$. Engl. J. Med., vol. 348, pp. 1953-1966.

[24] Phan, T., 2020. "Novel coronavirus: From discovery to clinical diagnostics." Infect. Genet. Evo., vol. 79, p. 104211. Available: https://doi.org/10.1016/j.meegid.2020.104211

[25] Brian, D. and Baric, R., 2005. "Coronavirus genome structure and replication." Curr. Top. Microbiol. Immunol., vol. 287, pp. 1-30. Available: https://doi.org/10.1007/3-540-26765-4_1

[26] Enyoh, C. E., Andrew, W. V., Wang, Q., Dipak, K. Y., Chowdhury, M. A. H., Beniah, O. I., Tanzin, C., Francis, C. I., Evelyn, N. V., et al., 2020a. "Indirect exposure to novel coronavirus (SARS-CoV-2): An overview of current knowledge." Preprints, Available: http://10.20944/preprints202004.0460.v1

[27] Islam, M. S., Sobur, M. A., Akter, M., Nazir, K. H. M. N. H., Toniolo, A., and Rahman, M. T., 2020. "Coronavirus disease 2019 (COVID-19) pandemic, lessons to be learned!" J. Adv. Vet. Anim. Res., vol. 7, pp. 260-280. Available: http://doi.org/10.5455/javar.2020.g418

[28] Backer, J. A., Klinkenberg, D., and Wallinga, J., 2020. "Incubation period of 2019 novel coronavirus (2019-nCoV) infections among travellers from Wuhan, China." Eurosurveillance, vol. 25, p. 2000062.

[29] Huang, C., Wang, Y., Li, X., Ren, L., Zhao, J., Hu, Y., Zhang, L., Fan, G., Xu, J., et al., 2020. "Clinical features of patients infected with 2019 novel coronavirus in Wuhan, China." Lancet, vol. 395, pp. 497-506.

[30] Heymann, D. L. and Shindo, N., 2020. "COVID-19: what is next for public health?" The Lancet, vol. 395, pp. 542-545. Available: https://doi.org/10.1016/S0140-6736(20)30374-3

https://economictimes.indiatimes.com/magazines/panache/covid-19-boost-your-immunity-with-dalmia-groupsherbal-capsule/articleshow/74684873.cms

[31] WHO, 2019. "Report of the WHO-China joint mission on coronavirus dis 7 ease 2019 (COVID-19)." Available: https://www.who.int/docs/default-source/coronaviruse/who-china-joint-mission-on-covid-19final-report.pdf

[32] NCDC, 2020. "Covid-19 Nigeria." Available: https://covid19.ncdc.gov.ng/

[33] Walker, L. M. and Burton, D. R., 2018. "Passive immunotherapy of viral infections: 'super-antibodies' enter the fray." Nature reviews, Immunology, vol. 18, pp. 1-13.

[34] Lin, L., Han, Y., and Yang, Z. M., 2003. "Clinical observation on 103 patients of severe acute respiratory syndrome treated by integrative traditional Chinese and Western medicine. Zhong guo Zhong Xi Yi Jie He Za Zhi." vol. 23, pp. 409-413. 
[35] Xiao, Z., Li, Y., Chen, R., Li, S., Zhong, S., and Zhong, N., 2003. "A retrospective study of 78 patients with severe acute respiratory syndrome." Chin. Med. J., vol. 116, pp. 805-810.

[36] Zhao, C. H., Guo, Y. B., Wu, H., Li, X. H., Guo, X. H., Jin, R. H., Dign, H. G., Meng, Q. H., Lang, Z. W., et al., 2003. "Clinical manifestation, treatment, and outcome of severe acute respiratory syndrome: analysis of 108 cases in Beijing." Zhonghua Yi Xue Za Zhi., vol. 83, pp. 897-901.

[37] Zhong, N. S. and Zeng, G. Q., 2003. "Our strategies for fighting severe acute respiratory syndrome (SARS) " Am. J. Respir. Crit. Care Med., vol. 168, pp. 7-9.

[38] Traffic, 2020. Available: https://www.traffic.org/news/covid-19-the-role-of-wild-plants-in-healthtreatment/

[39] Bangkokpost, 2020. "Covid-19 fear fuels rush for traditional herbal medication." Available: https://www.bangkokpost.com/thailand/general/1880490/covid-19-fear-fuels-rush-for-traditional-herbalmedication

[40] Economic times. Available: https://economictimes.indiatimes.com/magazines/panache/covid-19-boostyour-immunity-with-dalmia-groups

[41] Nytimes, 2020. Available: https://www.nytimes.com/reuters/2020/03/21/world/americas/21reuters-healthcoronavirus-bolivia-tradition.html

[42] Middleeasteye, 2020. Available: https://www.news24.com/Africa/News/madagascar-anti-virus-brews-selllike-hot-cakes-in-local-markets-20200326

[43] Langner, E., Greifenberg, S., and Gruenwald, J., 1998. "Ginger: historyand use." Advances in Therapy, vol. 15 , pp. $25-44$.

[44] Jung, S. C., Kuo, C. W., Chia, F. Y., Den, E. S., and Lien, C. C., 2013. "Fresh ginger (Zingiberofficinale) has anti-viral activity against human respiratory syncytial virus in human respiratory tract celllines." Journal of Ethnopharmacology, vol. 145, pp. 146-151.

[45] Thirumalaisamy, R., Murugan, P., Srinivasan, P., Arjunan, S., and Selvankumar, T., 2020. "Phytochemical 6-Gingerol - A promising Drug of choice for COVID." Int. J. Adv. Sci. Eng., vol. 6, pp. 1482-1489.

[46] Jung-Ho, K., Jeong, M. S., Na-Hyung, K., Mariadhas, V. A., Sunggil, K., Moo, K. Y., and Sun-Ju, K., 2017. "Variation of quercetin glycoside derivatives in three onion (Allium cepa L.) varieties." Saudi. J. Biol. Sci., vol. 24, pp. 1387-1391.

[47] Saba, A., Zolfaghar, R., and Mehdi, V. M., 2018. "Evaluation of the antiviral effects of aqueous extracts of red and yellow onions (Allium Cepa) against avian influenza virus subtype H9N2." Iranian Journal of Veterinary Science and Technology, vol. 2, pp. 1-11.

[48] Lamb, R. A. and Choppin, P. W., 1983. "The gene structure and replication of influenza virus." Annu. Rev. Biochem., vol. 52, pp. 467-506.

[49] Lanzotti, V., 2006. "The analysis of onion and garlic." J. Chromatogr. A. A., vol. 1112, pp. 3-22.

[50] Neha, S., 2019. "Efficacy of Garlic and Onion against virus." J. Res. Pharm. Sci., vol. 10, pp. 3578-3586.

[51] Mehrbod, P., Amini, E., and Tavassoti-Kheiri, M., 2009. "Antiviral activity of garlic extract on Influenza virus." Iranian Journal of Virology, vol. 2, pp. 8-15.

[52] Barrett, B., 2003. "Medicinal properties of Echinacea: a critical review." Phytomedicine, vol. 10, pp. 66-86.

[53] Burger, A., Torres, A. R., Warren, R. P., Caldwell, V. D., and Hughes, B. G., 1997. "Echinacea-induced cytokine production by human macrophages." Int. J. Immunopharmacol., vol. 19, pp. 371-379.

[54] Binns, S. E., Hudson, J., Merali, S., and Arnason, J. T., 2002. "Antiviral activity of characterized extracts from Echinacea spp. (Heliantheae: Asteraceae) against herpes simplex virus (HSV-1)." Planta. Med., vol. 68, pp. 780-783.

[55] Ali, M. Z., Mehmood, M. H., and Saleem, M., 2020. "The use of Euphorbia hirta L. (Euphorbiaceae) in diarrhea and constipation involves calcium antagonism and cholinergic mechanisms." BMC Complement Med Ther, vol. 20, pp. 4-9.

[56] Yoshida, T., Chen, L., Shingu, T., and Okuda, T., 1988. "Tannins and related polyphenols of euphorbiaceous plants iv. Euphorbins a and b, novel dimericdehydroellagitannins from euphorbia hirta." Chem. Pharm. Bull., vol. 36, pp. 2940-2949.

[57] Liu, Y., Murakami, N., Ji, H., Abreu, P., and Zhang, S., 2007. "Antimalarial flavonol glycosides from Euphorbia hirta." Pharm. Biol., vol. 45, pp. 278-281.

[58] Zhao, Y., Wang, Y., Ye, D. W., Yan, S. J., Liu, J. P., Pu, J. X., Du, X., Wang, J. H., and Chen, Y. G., 2012. "Benzoic glycoside from Euphorbia hirta." J. Chem. Soc. Pakistan, vol. 34, pp. 223-5.

[59] Galvez, J., Zarzuelo, A., Crespo, M., and Jiménez, J., 1993. "Antidiarrhoeic activity of quercitrin in mice and rats." J. Pharm. Pharmacol., vol. 45, pp. 157-9.

[60] Anand, V., Juveriyah, K., Durai, M., and Agaath, H. S., 2016. "Review of the phytochemical and pharmacological activities of Euphorbia hirta Linn." Pharmacogn J., vol. 8, pp. 310-3.

[61] Ágnes, G., László, S., János, M., Andrea, V., Joseph, M., and Judit, H., 2009. "Antiviral activities of extracts of euphorbia hirta 1. Against hiv-1, hiv-2 and sivmac 251." International Journal of Experimental and Clinical Pathophysiology and Drug Research, vol. 23, pp. 429-432.

[62] Dalziel, J. M., 1937. The useful plants of west tropical Africa. London: Crown Agents for the Colonies.

[63] Iwu, M., 1993. Handbook of African medicinal plants vol. 12. Boca Raton, FL.: CRC Press. pp. 32-38.

[64] Adesina, S. K., Gbile, Z. O., and Odukoya, O. A., 1995. Survey of indigenous plants of West Africa with special emphasis on medicinal plants and issues associated with management. 2nd ed. The United Nations Programme on Natural Resources in Africa, pp. 84-5. 
[65] Ayensu, E. S., 1978. Medicinal plants of West Africa. Algonac, Michigan: Reference Publ.Inc. p. 162.

[66] Ifeoluwa, O. A., Olaleye., D. O., and Ebenezer, O. F., 2015. "Kolaviron improves morbidity and suppresses mortality by mitigating Oxido-Inflammation in BALB/c Mice Infected with Influenza." VirusViralImmunol, vol. 28, pp. 367-377.

[67] Dony, C. M. and Wei-Li, H., 2018. "Antiviral potential of curcumin." Journal of Functional Foods, vol. 40, pp. 692-699.

[68] Marshall, J. M., 1990. "Aloe vera gel: What is the evidence?" Pharma. Jr., vol. 24, pp. 360-2.

[69] Keivan, Z., Moloud, A. Z., Kohzad, S., and Zahra, R., 2007. "Antiviral activity of Aleovera against herpes simplex virus type 2: An in vitro study." African Journal of Biotechnology, vol. 6, pp. 1770-1773.

[70] Ambrish, K. S., Kumar., A., and Neeraj, M., 2020. "On the Inhibition of COVID-19 Protease by Indian Herbal Plants: An In Silico Investigation." Available: https://arxiv.org/ftp/arxiv/papers/2004/2004.03411.pdf

[71] Eduardo, M., Concepción, R., Pedro, G., and Manuel, B., 2019. "Characterization of bioactive compounds in commercial olive leaf extracts, and olive leaves and their infusions." Royal Society of Chemistry, vol. 10, pp. 4716-4724.

[72] Motamedifar, M., Nekooeian, A. A., and Moatari, A., 2007. "The effect of hydroalcoholic extract of olive leaves against herpes simplex virus type 1." I. J. M. S., vol. 32, p. 4.

[73] Syed, H. O., 2010. "Oleuropein in olive and its pharmacological effects." Sci. Pharm., vol. 78, pp. $133-154$. 